\title{
Using information and communication technology in the recovery after a coronary artery bypass graft surgery: patients' attitudes
}

This article was published in the following Dove Press journal: Journal of Multidisciplinary Healthcare

\author{
Jan Gunnar Dale' \\ Elin Midthus ${ }^{2}$ \\ Bjørg Dale ${ }^{3}$
}

'University of Agder, Institute of Health and Nursing Science, Grimstad, Norway; ${ }^{2}$ LHL Hospital Gardermoen, Jessheim, Norway; ${ }^{3}$ Centre for Care Research, Southern Norway, University of Agder, Grimstad, Norway
Correspondence: Jan Gunnar Dale University of Agder, Institute of Health and Nursing Science, Post Box 509, NO-4898 Grimstad, Norway

Tel +473723 373I

Email jan.g.dale@uia.no
Background: Patients who have undergone a coronary artery bypass graft (CABG) surgery are exposed to physical and mental problems after discharge from the specialist hospital and are often in need of post-discharge support and follow-up.

Aim: This study aimed to explore the attitudes of CABG patients toward using information and communication technology (ICT) during the first year of recovery after discharge from hospital. Methods: A cross-sectional design utilizing an electronic survey was employed. The sample consisted of 197 patients who had undergone a CABG surgery during 2015. The questionnaire included questions about follow-up needs, contacts with health professionals, use of the Internet, and attitudes toward using ICT in the recovery phase.

Results: Mean age of the participants was 67.3 years; $18.3 \%$ were women. A total of $48.2 \%$ of the patient group was satisfied with the pre-discharge information. Only $27 \%$ had contacted the hospital after discharge. Whereas $58.4 \%$ of the participants had used the Internet to acquire information, only $30.4 \%$ found this information to be useful. Many patients (40\%) reported that they could benefit from online health information and Skype meetings with professionals. More than $30 \%$ reported that nutritional guidance on the Internet could be motivating for choosing healthy diets, and $42.6 \%$ reported that Internet-based illustrative videotapes could be motivating for undertaking physical training.

Conclusion: ICT can be useful and resource-saving for patients who have undergone a CABG surgery, as well as for the health care services. The technology must be appropriately tailored, with regard to content and design, to be helpful for patients.

Keywords: attitudes, cross-sectional, lifestyle changes, motivation

\section{Introduction}

Coronary artery bypass graft (CABG) surgery is a common, and often successful, treatment of patients suffering from severe cardiac disease. ${ }^{1}$ However, the hospital stay for $\mathrm{CABG}$ patients after surgery is becoming increasingly shorter during the last decades, for reducing hospital costs, ${ }^{2}$ which causes several challenges and problems for both patients and their caregivers after hospital discharge, as they return home more sick and unprepared to handle everyday life than they were before. ${ }^{3}$ Consequently, many patients in this group need professional follow-up and support after returning home.

\section{Background and literature review}

CABG surgery is an effective cardiac treatment, the prognosis is promising, and it is found to improve the life quality and functioning for many patients. ${ }^{4}$ However, the 
treatment is associated with major challenges, and mental as well as physical symptoms are common, particularly within the first weeks of recovery. ${ }^{4}$ Anxiety, depression, sleep disturbance, pain, fatigue, and uncertainty with regard to exercising and activity, nutrition, sexuality, medication, and wound care are some of the major problems reported. ${ }^{3,5}$ In addition, the closest relatives, particularly spouses, who often act as caregivers for the patients during the recovery period, have also reported unpreparedness and increased levels of anxiety and depression. ${ }^{6}$

Providing adequate information to the patients and next of kin before discharge is crucial in decreasing post-discharge problems. Although hospital staff in many hospitals and hospital wards who are treating patients for CABG surgery have well-established routine pre-discharge information, the patients' shortened length of hospital stay probably affects the staff's ability to provide individualized information, advice, and education. Additionally, patients and next of kin might still be overwhelmed by mental and physical impacts of undergoing $\mathrm{CABG}$, making it hard to retain very much of the information provided in a limited time frame. Because many CABG patients are old, they are also particularly vulnerable due to age-related comorbidities, which might increase the complication rate post-surgery. ${ }^{7}$

It is important that postoperative information and education is individualized, using multiple delivery means - both verbal and written - and that information delivery occurs in multiple sessions. ${ }^{8}$ Still, there might be a disconnect between patient needs and the professional provider's appraisal of the information content, and too much information may be provided in written format that fails to account for the patients' health literacy level. ${ }^{9}$ On the other hand, verbalonly instructions tend to be forgotten or not remembered accurately, and discrepancy between providers' and patients' readiness is common. ${ }^{9}$ Consequently, there might be a risk that the CABG patients' needs for information and counseling before discharge from the hospital are insufficiently met and that they will need follow-up after returning home.

Follow-up of patients who have undergone advanced cardiac surgery should preferably be conducted by specially trained nurses, who have necessary professional knowledge of heart disease, the surgery that the patient has undergone, what can be expected, and how to manage everyday life after returning home. ${ }^{10}$ In addition, health professionals who are responsible for patient information, education, motivation, and lifestyle counseling need advanced communication and patient education skills. ${ }^{11}$ Such skills include the ability to establish an interpersonal relationship and identify the patients' ability to learn. ${ }^{11}$ Ideally, this follow-up should be undertaken by the hospital staff, who have special knowledge and are well trained to conduct follow-up, and who know the patients.

However, geographic and transportation barriers between the patients' home and the hospital might be a challenge when it comes to opportunities for follow-up information and support, and, thus, new approaches are needed. ${ }^{9}$ Costeffective communications technologies, such as the Internet and tele-health, are developing rapidly, and provide a range of new opportunities for patient communication and interaction with health professionals despite geographic distances. ${ }^{12,13}$

New media play an increasing role in the everyday life even for older individuals, as they extensively use the Internet, patient portals, and mobile phone applications to search for health-related information. ${ }^{14}$ In a systematic review, Bolle et $\mathrm{al}^{14}$ found that Internet-based information tools might be effective in improving self-efficacy in older patients. However, they also found that the usability of such tools, which seemed to be an important prerequisite for success, were often unsatisfactory and insufficiently described in the studies.

The use of information technology in the health care sector is described as a strategic focus area in Norwegian public documents, ${ }^{15}$ but efforts to implement digital solutions in health care have lagged behind other sectors. ${ }^{16}$ Patients have had access to health information on the Internet for a long time, but a two-way digital communication with professionals aimed to interact with, and support patients living in their own homes, is rarely implemented in Norway. ${ }^{16}$ Additionally, knowledge about patients' preferences and attitudes toward using communication technology to acquire information and interact with health professionals is sparse.

Therefore, this study aimed to explore the attitudes of CABG patients toward using information and communication technology (ICT) during the first year of recovery after discharge from hospital.

\section{Materials and methods}

In the current study, ICT is defined as e-learning (eg, educational videotapes for exercising), available websites (eg, the hospital's website or the National Organization for Heart and Lung Diseases' website), net fora for communication with health professionals and peers (other patients in the same situations and their next of kin), and Skype meetings (to communicate with a nurse at the hospital).

This study employed a cross-sectional design utilizing an electronic survey. 


\section{Sample and setting}

The study was conducted among patients who had undergone a $\mathrm{CABG}$ surgery in a private specialist hospital in eastern Norway, hosting patients from all over the country. Most patients are transferred to a local hospital for a short period of time after discharge and before returning home. The hospital has protocols to provide pre-discharge information and counseling to patients and next-of-kin, and they offer an open telephone line for patients who need to contact the hospital after they have returned home.

All patients who had undergone a CABG surgery at the actual hospital in 2015 ( $n=309)$ were invited to participate in the study. The patients received an email request to participate, together with the questionnaire. Seventy-one patients (23\%) answered the questionnaire in the first round. One reminder was sent out after 1 month, resulting in additionally 126 responses. Thus, the final sample included 197 patients - that is, $64 \%$ of those initially invited. In the responding group, $18.3 \%$ were women and the mean age of the patients was 66.2 years.

\section{Data collection}

Eligible patients were identified by staff persons at the hospital who were not directly involved in the study, and all patients were informed of the study in advance by means of an information letter. The electronic questionnaire SurveyXact was used for data collection, and return of answered forms was considered as consent to participation.

\section{Study questionnaire}

The questionnaire used was designed for this study. It consisted of sociodemographic questions (ie, gender, age, civil state, educational level), length of the hospital stays (days), and time since surgery (weeks). Questions were asked about the information the patient received before discharge from the hospital, and how much they remembered after they got home. In addition, they were asked what information needs they experienced after returning home. The questionnaire assessed their post-discharge contacts with health professionals in the municipalities, and nurses at the specialist hospital. They were asked whether they had used websites, and which ones if they did, to answer their health questions and concerns. Perceptions of their current health state were assessed (options ranging from very poor to very good), and the presence of fatigue, depressive or anxiety symptoms, and pain-related uncertainty during the first weeks after returning home (options ranging from very much to not at all). Opinions about whether and to what degree ICT could meet the need for information and motivation for changing lifestyle were assessed, as were perceived benefits of Skype meetings with the hospital staff. Some of the questions had the response options yes/no, whereas a 5-point Likert scale (eg, with options ranging from "very little" to "very much", or from "I totally disagree" to "I totally agree") were mostly used.

\section{Analyses}

IBM SPSS statistical software version 24 (Armonk, NY, USA) was used to conduct the statistical analyses. The significance level was set at $P$-value $<0.05$.

Descriptive statistics were used to display an overview of the participants' characteristics with regard to gender, age, educational level, marital state, time since surgery, and length of hospital stay. Moreover, descriptive statistics were used to present the patients' satisfaction with the pre-discharge information and counseling, and how much they remembered after they got home. Further, descriptive statistics were used to display whether they had contacted the GP, the community health services, and the specialist hospital with regard to their own health. Non-parametric statistics with Mann-Whitney $U$-tests were used to explore differences between groups.

Linear regression analyses were conducted to investigate possible predictors of the patients' opinions about whether ICT could meet the need for information, motivation for changing lifestyle, and the benefits of Skype meetings with the hospital staff. The independent variables included in the models showed significant $P$-values in prior univariate analyses.

\section{Ethical considerations}

The study was approved by the Norwegian Center for Research Data (ref. no 45806). Approval was also given by the hospital's authorities. The study participants' ethical rights pertaining to voluntariness, anonymity, and right to withdraw at any time ${ }^{17}$ were underlined in the information letter attached to the questionnaire. Completed and returned questionnaires were considered as provision of informed consent to participate in the study. The investigation conforms with the principles outlined in the Declaration of Helsinki. ${ }^{18}$

\section{Results}

The participants' age ranged from 44 to 85 years ( $M=67.3$; $\mathrm{SD}=8.35$ ). Background information of the sample is displayed in Table 1.

A total of 149 patients $(75.6 \%)$ were satisfied with the information and counseling they received before discharge 
Table I An overview of the patients' sociodemographics

\begin{tabular}{|c|c|c|}
\hline Variables & $\mathbf{n}$ & $\%$ \\
\hline \multicolumn{3}{|l|}{ Gender $(n=197)$} \\
\hline Women & 36 & 18.3 \\
\hline Men & 161 & 81.7 \\
\hline \multicolumn{3}{|l|}{ Age groups $(n=197)$} \\
\hline $40-50$ years & 7 & 3.6 \\
\hline $51-60$ years & 36 & 18.3 \\
\hline $6 I-70$ years & 83 & 42.1 \\
\hline $7 I-80$ years & 62 & 31.5 \\
\hline $81-90$ years & 9 & 4.6 \\
\hline \multicolumn{3}{|l|}{ Educational level $(n=196)$} \\
\hline Primary school & 45 & 22.8 \\
\hline Secondary school & 58 & 29.4 \\
\hline University/university college & 73 & 37.1 \\
\hline Else & 20 & 10.1 \\
\hline Missing & 1 & 0.5 \\
\hline \multicolumn{3}{|l|}{ Marital state $(n=197)$} \\
\hline Married & 130 & 66 \\
\hline Partnership & 16 & 8.1 \\
\hline In a relationship & 6 & 3.0 \\
\hline Widow/widower & 14 & 7.1 \\
\hline Divorced & 19 & 9.6 \\
\hline Single (never married) & 12 & 6.1 \\
\hline \multicolumn{3}{|l|}{ Time since surgery $(n=194)$} \\
\hline 4-12 weeks & 34 & 17.3 \\
\hline 13-26 weeks & 53 & 26.9 \\
\hline 27-39 weeks & 49 & 24.9 \\
\hline$>40$ weeks & 61 & 31.0 \\
\hline \multicolumn{3}{|l|}{ Length of hospital stay $(n=193)$} \\
\hline $\mathrm{I}-3$ days & 109 & 55.3 \\
\hline $4-5$ days & 74 & 37.6 \\
\hline $6-10$ days & 6 & 3.0 \\
\hline$>10$ days & 4 & 2.0 \\
\hline
\end{tabular}

from the hospital. After they had returned home, $62.5 \%$ of the patients remembered the information provided by the nurse, $54.3 \%$ remembered the information provided by the doctor, and $67.0 \%$ remembered the information provided by the physiotherapist. Further, 171 persons $(86.8 \%)$ had contacted the community GP, and $46.7 \%$ of this group were satisfied with the response and help they received from the GP. A total of 118 persons (60\%) had contacted the community health services after discharge, whereas $27.4 \%$ of the patients had contacted the specialist hospital about questions with regard to their health. Those who had contacted the hospital were older $(P=0.042)$, more worried $(P=0.040)$, and more insecure about their own condition after discharge $(P=0.040)$, respectively, than those who had not contacted the hospital. Common questions or concerns were about medication, surgery wounds, pain, compression stockings, physical activities, and other unspecified issues.
A total of 115 patients (58.4\%) had used the Internet to require information about their cardiac disease, and 30.5\% found this information to be useful - to a great or very great degree, $32 \%$ answered neither/nor, and $36.5 \%$ answered to a little or very little degree. The patients who had used the Internet for information were younger $(P=0.002)$ than those who had not used such information sources. The analyses revealed no statistical differences on internet or technology use with regard to gender, marital state, and educational level in the sample group.

A total of $46 \%$ of the patients reported that e-learning would, to a high or very high degree, provide increased knowledge of heart disease, and 54\% reported that they would have benefited from a website that contains answers to frequently asked questions (FAQs) about the disease. A total of $40 \%$ reported that Skype communication with a nurse at the specialist hospital would, to a high or very high degree, be helpful the first week after discharge for discussing own life situation, and $40 \%$ believed that ICT in general could accommodate the need for information and guidance. Further, $27 \%$ reported that ICT could be motivating for changing lifestyle after returning home, $32.5 \%$ reported that nutritional guidance on the Internet could be motivating for choosing healthy diets, and $42.6 \%$ reported that internet-based illustrative videotapes could be motivating for carrying out physical training. Patients' opinions about the benefits of using ICT, and related predictors, are presented in Table 2.

Lower age was weakly associated with the variable "Digital communication could cover need for information and counseling" in the correlation analysis $(r s=-0.308 ; P<0.001)$, but age did not come up as a predictor for attitudes toward using digital communication in the regression analyses.

A total of $61.4 \%$ of the patient group perceived that it would be economically advantageous to use ICT to interact with health care professionals from home.

\section{Discussion}

This study aimed to explore the attitudes of patients, who have undergone a CABG surgery, toward using ICT during the first year of recovery after discharge from the hospital.

Although the actual hospital offers an open telephone line for patients who need to contact the hospital after they have returned home, only $27 \%$ of the patients in this study had taken advantage of this offer. At the same time, the results indicate that many of the participants would benefit from maintaining such contact with the hospital staff after returning home. One reason why they had not contacted 
Table 2 Predictors for patients' opinions of ICT benefits in the recovery phase

\begin{tabular}{|c|c|c|c|}
\hline Dependent variables & Predictors & Beta & P-value \\
\hline ICT could cover need for & Own network encourages use of online communication with the hospital's nurse & 0.203 & $<0.001$ \\
\hline information and counseling & FAQs on a website with nurses' responses about cardiac disease could be useful & 0.176 & 0.003 \\
\hline \multirow[t]{2}{*}{$R^{2}=0.66$} & ICT could be motivating for changing lifestyle & 0.265 & $<0.001$ \\
\hline & E-learning provides knowledge about cardiac disease & 0.263 & $<0.001$ \\
\hline Skype meetings with a & Network encourages use of online communication with the hospital's nurse & 0.425 & $<0.001$ \\
\hline nurse at the specialist & FAQ on a website with nurses' responses about cardiac disease could be useful & 0.186 & 0.020 \\
\hline hospital after discharge & Feeling depressed & 0.187 & 0.009 \\
\hline \multirow[t]{2}{*}{ could be helpful $R^{2}=0.54$} & Need information about sexuality & 0.182 & 0.003 \\
\hline & Have contacted specialist hospital after discharge & 0.129 & 0.015 \\
\hline ICT could be motivating for & Internet based nutritional guidance could be motivating for the choice of healthy diets & 0.345 & $<0.001$ \\
\hline \multirow[t]{3}{*}{ changing lifestyle $R^{2}=0.64$} & Internet-based illustrative videotapes could be motivating for carrying out physical training & 0.180 & 0.009 \\
\hline & ICT could cover need for information and counseling & 0.254 & 0.001 \\
\hline & Higher education & -0.116 & 0.012 \\
\hline
\end{tabular}

Abbreviations: FAQs, frequently asked questions; ICT, information and communication technology.

the hospital could be that approximately half of the patient group was satisfied with the pre-discharge information and guidance they received. Moreover, most of the patients had contacted their GP after discharge, and most of them were satisfied with this contact. Another explanation might be that they perceived the threshold for contacting the hospital staff as high. Keeping-Burke et $\mathrm{al}^{6}$ found that patients who are followed up by the hospital nurse the first weeks after discharge, combined with audiovisual sessions, had fewer contacts with their GP. In addition, family caregivers had less depressive and anxiety symptoms compared to those who did not receive such follow-up.

Less than half of the patients in this study reported that Skype meetings with a nurse at the specialist hospital after discharge would be helpful or very helpful. Similarly, less than half of the group thought that ICT could be useful for obtaining information and guidance about appropriate lifestyle, including nutrition and physical activity guidance. Explanations to these results might be the same as the above mentioned, which is that many patients were satisfied with the pre-discharge information and guidance they had received, or that they were satisfied with the follow-up by the municipal health services. Another explanation could be that they were unfamiliar with using ICT and that they were unaware of how to use it. Further, former negative experiences with using ICT could also influence their attitudes, and the study results indicate that some of the patients who had used the Internet to obtain information about their health condition found it only partially useful. For instance, the content and design of the solutions could be experienced as inappropriate and not user-friendly. The study by Lie et $\mathrm{al}^{3}$ showed that patients who had undergone a CABG surgery wanted an opportunity for follow-up from a cardiac care nurse at the hospital, particularly in the first month after discharge. Anxiety, uncertainty, and depression are common symptoms following $\mathrm{CABG}$ surgery, and many patients experience several postoperative symptoms and complications which might delay their recovery. ${ }^{3,19}$ It is recommended that hospital staff (nurses) respond to patients" questions related to lifestyle, and provide training, counseling, and follow-up after discharge, ${ }^{13}$ as this could increase the patients' quality of life. In addition, the study by Bikmoradi et $\mathrm{a}^{20}$ showed that telephonic counseling increased the CABG patients' quality of life, both physically and emotionally.

Exercise-based cardiac rehabilitation appears to be crucial for reducing cardiovascular mortality and hospital readmissions, and for improving patients' health conditions and quality of life after discharge. ${ }^{21}$ Further, symptoms management in the recovery phase after CABG surgery (eg, fatigue, pain, breathlessness, and sleep problems) is essential for physiological and psychosocial functioning, particularly for older patients. ${ }^{22}$ However, although beneficial effects of patient participation in cardiac rehabilitation programs exist, and were also demonstrated in a robust research body, the participation referral and attendance to these program remains low. ${ }^{21,23}$ For patients who have undergone a heart surgery, the recovery period might often be stressful, and the first weeks after returning home are particularly associated with several physical and psychological challenges. ${ }^{24}$ Important reasons for not accepting the invitation to attend cardiac rehabilitation are difficulties in regularly attending sessions at their local hospital, and hesitancy to participate in group-based classes. ${ }^{23}$ In this sense, home-based telehealth exercise programs are found to be beneficial for patients who cannot attend in-hospital or center-based rehabilitation programs, and at least as effective. $23,25,26$ 
Many participants in our study perceived that ICT, such as e-learning, use of the Internet, and audio/videotapes, could be effective and beneficial modes to gain knowledge about heart disease, and that it could be motivating for changing lifestyle (eg, diet and physical activity). More than half of the group believed that they would benefit from an FAQs website. Using pre-prepared audiotaped information programs is found to decrease the level of anxiety and depression ${ }^{4}$ and physical symptoms such as pain, loss of appetite, and inactivity ${ }^{24}$ in the patients' recovery period after CABG surgery.

Communication technology, such as the Internet, is a low-cost offer providing patients with opportunities to communicate with health professionals while bridging geographic distances, and without requiring face-to-face meeting. ${ }^{12}$ However, Jenssen et $\mathrm{al}^{27}$ showed that more patients preferred to use e-mail or face-to-face communicating with the GP about their health and health care rather than using social media or text messaging.

There was no convincing relationship between age and attitudes toward using communication technology in the current study group. However, it is important to note that few of the patients were in the oldest age group. Nevertheless, although a large part of the older population now has access to the Internet and uses the Internet regularly to search for health information, they are generally less experienced than younger people. ${ }^{14}$ Therefore, it is important that information and communication technologies are tailored according to the patients' needs and abilities when it comes to content as well as usability and design.

\section{Conclusion and methodological considerations}

This study focused on the attitudes of patients who had undergone CABG surgery toward the use of ICT as a mode for obtaining information and knowledge, and interacting with health professionals, after returning home. A significant proportion of the participating patients had used the Internet to acquire information about their cardiac disease, but many of them found that this had not been particularly useful. Although the participants' perceptions varied, the results indicate that many of them reported digital communication and information could be useful in the recovery after the CABG surgery. However, it appears decisive that the digital tools are appropriate, and patient centered, with regard to content and design.

The quantitative design with the use of a questionnaire did not allow for in-depth information or explanations related to the participants' answers. This should be further investigated in new studies. The sample size was limited and included participants treated in one specialist hospital, which might also represent a limitation of this study. Characteristics of the sample seem to correspond well with the total group invited to participate with regard to mean age and gender distribution. Supplementary information about the dropouts is not available, but the results could have been different if more patients had been included. However, this study provides valuable and new knowledge about how a group of patients assess the benefits of using health-related ICT in the recovery phase after a CABG surgery. Thus, the results represent important contributions, and motivation, to further develop well-designed and appropriate technologies that can support patients to manage everyday life after discharge.

\section{Acknowledgment}

This research did not receive any specific grants from any funding agency in the public, commercial, or not-for-profit sectors.

\section{Disclosure}

The authors report no conflicts of interest in this work.

\section{References}

1. Gallagher R, Mckinley S. Anxiety, depression and perceived control in patients having coronary artery bypass grafts. $J$ Adv Nurs. 2009;65(11):2386-2396.

2. Li Y, Cai X, Mukamel DB, Cram P. Impact of length of stay after coronary bypass surgery on short-term readmission rate: an instrumental variable analysis. Med Care. 2013;51(1):45-51.

3. Lie I, Bunch EH, Smeby NA, Arnesen H, Hamilton G. Patients' experiences with symptoms and needs in the early rehabilitation phase after coronary artery bypass grafting. Eur J Cardiovasc Nurs. 2012;11(1):14-24.

4. Hoseini S, Soltani F, Babaee Beygi M, Zarifsanaee N. The effect of educational audiotape programme on anxiety and depression in patients undergoing coronary artery bypass graft. J Clin Nurs. 2013;22(11-12): 1613-1619.

5. Ammouri AA, Al-Daakak ZM, Isac C, Gharaibeh H, Al-Zaru I. Symptoms Experienced by Jordanian Men and Women After Coronary Artery Bypass Graft Surgery. Dimens Crit Care Nurs. 2016;35(3):125-132.

6. Keeping-Burke L, Purden M, Frasure-Smith N, et al. Bridging the transition from hospital to home: effects of the VITAL telehealth program on recovery for CABG surgery patients and their caregivers. Res Nurs Health. 2013;36(6):540-553.

7. Natarajan A, Samadian S, Clark S. Coronary artery bypass surgery in elderly people. Postgrad Med J. 2007;83(977):154-158.

8. Fredericks S, Guruge S, Sidani S, Wan T. Postoperative patient education: a systematic review. Clin Nurs Res. 2010;19(2):144-164.

9. Cook DJ, Moradkhani A, Douglas KS, et al. Patient education selfmanagement during surgical recovery: combining mobile (iPad) and a content management system. Telemed J E Health. 2014;20(4):312-317.

10. Sawatzky JA, Christie S, Singal RK. Exploring outcomes of a nurse practitioner-managed cardiac surgery follow-up intervention: a randomized trial. J Adv Nurs. 2013;69(9):2076-2087. 
11. Svavarsdóttir MH, Sigurðardóttir ÁK, Steinsbekk A. Knowledge and skills needed for patient education for individuals with coronary heart disease: The perspective of health professionals. Eur J Cardiovasc Nurs. 2016;15(1):55-63.

12. Lear SA, Singer J, Banner-Lukaris D. Improving Access to Cardiac Rehabilitation Using the Internet: A Randomized Trial. Global Telehealth 2015: Integrating Technology and Information for better Healthcare. Gillis G, Newsham D, Maeder AJ, editors. Amsterdam: IOS Press BV; 2015:58-66.

13. Bikmoradi A, Masmouei B, Ghomeisi M, Roshanaei G. Impact of Tele-nursing on adherence to treatment plan in discharged patients after coronary artery bypass graft surgery: A quasi-experimental study in Iran. Int J Med Inform. 2016;86:43-48.

14. Bolle S, van Weert JC, Daams JG, et al. Online Health Information Tool Effectiveness for Older Patients: A Systematic Review of the Literature. J Health Commun. 2015;20(9):1067-1083.

15. Ministry of Health and Care Services. Report to the Storting no 10. (2012-2013). God Kvalitet - Trygge Tjenester - Kvalitet og Pasientsikkerhet $i$ Helse og Omsorgstjenesten. In: Norwegian: High Quality - Safe Services - Quality and Patient safety in the Health and Care Services; 2012.

16. Berntsen G, Hasvold PE. New technology enables patients to become involved and engaged in their own health and ill-health. Quality standards and privacy must be ensured. J Norw Med Ass. 2015;135:828.

17. Beauchamp L, Childress JF. Principles of Biomedical Ethics. 7th ed. Oxford: Oxford University Press; 2013.

18. Rickham PP. Human experimentation. Code of ethics of the World Medical Association. Declaration of Helsinki. BMJ. 1964;2(5402):177.
19. Rollman BL, Belnap BH, Lemenager MS, Michelle S, et al. Telephonedelivered collaborative care for treating post-CABG depression: a randomized controlled trial. JAMA. 2009;302(19):2095-2103.

20. Bikmoradi A, Masmouei B, Ghomeisi M, Roshanaei G, Masiello I. Impact of telephone counseling on the quality of life of patients discharged after coronary artery bypass grafts. Patient Educ Couns. 2017;100(12):2290-2296.

21. Anderson L, Oldridge N, Thompson DR, et al. Exercise-Based Cardiac Rehabilitation for Coronary Heart Disease. J Am Coll Cardiol. 2016;67(1):1-12.

22. Barnason S, Zimmerman L, Nieveen J, et al. Influence of a symptom management telehealth intervention on older adults' early recovery outcomes after coronary artery bypass surgery. Heart Lung. 2009;38(5):364-376.

23. Taylor RS, Dalal H, Jolly K, et al. Home-based versus centre-based cardiac rehabilitation (review). CDSR. 2015;8.

24. Utriyaprasit K, Moore SM, Chaiseri P. Recovery after coronary artery bypass surgery: effect of an audiotape information programme. $J A d v$ Nurs. 2010;66(8):1747-1759.

25. Scalvini S, Zanelli E, Comini L, et al. Home-based versus in-hospital cardiac rehabilitation after cardiac surgery: a nonrandomized controlled study. Phys Ther. 2013;93(8):1073-1083.

26. Rawstorn JC, Gant N, Direito A, Beckmann C, Maddison R. Telehealth exercise-based cardiac rehabilitation: a systematic review and metaanalysis. Heart. 2016;102(15):1183-1192.

27. Jenssen BP, Mitra N, Shah A, Wan F, Grande D. Using Digital Technology to Engage and Communicate with Patients: A Survey of Patient Attitudes. J Gen Intern Med. 2016;31(1):85-92.
Journal of Multidisciplinary Healthcare

\section{Publish your work in this journal}

The Journal of Multidisciplinary Healthcare is an international, peerreviewed open-access journal that aims to represent and publish research in healthcare areas delivered by practitioners of different disciplines. This includes studies and reviews conducted by multidisciplinary teams as well as research which evaluates the results or conduct of such teams or health

\section{Dovepress}

care processes in general. The journal covers a very wide range of areas and welcomes submissions from practitioners at all levels, from all over the world The manuscript management system is completely online and includes a very quick and fair peer-review system. Visit http://www.dovepress.com/ testimonials.php to read real quotes from published authors. 